\title{
Pathophysiological properties of CLIC3 chloride channel in human gastric cancer cells
}

\author{
Shunsuke Kawai ${ }^{1 \dagger}$, Takuto Fujii ${ }^{2 \dagger}$, Takahiro Shimizu², Kenta Sukegawa ${ }^{1}$, Isaya Hashimoto ${ }^{1}$, Tomoyuki Okumura', \\ Takuya Nagata ${ }^{1}$, Hideki Sakai ${ }^{*}$ and Tsutomu Fujii ${ }^{1}$
}

\begin{abstract}
Pathophysiological functions of chloride intracellular channel protein 3 (CLIC3) in human gastric cancer have been unclear. In the tissue microarray analysis using 107 gastric cancer specimens, CLIC3 expression was negatively correlated with pathological tumor depth, and the patients with lower expression of CLIC3 exhibited poorer prognosis. CLIC3 was expressed in the plasma membrane of cancer cells in the tissue. CLIC3 expression was also found in a human gastric cancer cell line (MKN7). In whole-cell patch-clamp recordings of the cells expressing CLIC3, NPPB-sensitive outwardly rectifying $\mathrm{Cl}^{-}$currents were observed. Cell proliferation was significantly accelerated by knockdown of CLIC3 in MKN7 cells. On the other hand, the proliferation was attenuated by exogenous CLIC3 expression in human gastric cancer cells (KATOIII and NUGC-4) in which endogenous CLIC3 expression is negligible. Our results suggest that CLIC3 functions as a $\mathrm{Cl}^{-}$channel in the plasma membrane of gastric cancer cells and that decreased expression of CLIC3 results in unfavorable prognosis of gastric cancer patients.
\end{abstract}

Keywords: Cell proliferation, Chloride channel, Chloride intracellular channel protein, Gastric cancer, Prognosis

\section{Introduction}

Gastric cancer is one of the most common malignant tumors in the abdominal region $[1,2]$. Various treatments have been developed such as surgical resection, endoscopic therapy and chemotherapy [3-5]. However, the morbidity rate of gastric cancer has increased as the population ages [6]. Clarifying the mechanism of malignant traits is important to improve prognosis of gastric cancer.

So far, in gastric cancer, overexpression of several anion channels has been reported to be related to unfavorable prognosis of the patients: higher expression of chloride channel-3 (CLC-3) promotes cellular invasion in gastric cancer and predicts poor prognosis

\footnotetext{
*Correspondence: sakaih@pha.u-toyama.ac.jp

${ }^{\dagger}$ Shunsuke Kawai and Takuto Fujii contributed equally to this work ${ }^{2}$ Department of Pharmaceutical Physiology, Graduate School of Medicine and Pharmaceutical Sciences, University of Toyama, 2630 Sugitani, Toyama 930-0194, Japan

Full list of author information is available at the end of the article
}

[7]. Overexpression of transmembrane protein 16A (TMEM16A), a Ca ${ }^{2+}$-activated $\mathrm{Cl}^{-}$channel, also contributes to tumor invasion and poor prognosis of human gastric cancer [8]. Elevation of chloride intracellular channel 1 (CLIC1) is strongly correlated with lymph node metastasis, lymphatic invasion and pathological staging in gastric cancer [9].

Based on previous reports of anion channels described above, we tried to clarify pathophysiological functions of other anion channels in gastric cancer. The CLIC family is known to consist of six human members and to be a subgroup of the glutathione-S-transferase superfamily [10]. On the other hand, it has been reported that chloride intracellular channel 3 (CLIC3) plays roles as not only a soluble protein, but also an organellar membrane protein [10-12]. Moreover, CLIC3 is associated with poor prognosis in pancreatic cancer, breast cancer, ovarian cancer, and malignant pleural mesothelioma [13-17]. Taken together, we have raised two questions: (1) Does CLIC3 act as a $\mathrm{Cl}^{-}$channel in the membrane?, and (2) 
Is CLIC3 expression associated with prognosis of gastric cancer?.

In the present study, we therefore investigated expression and function of CLIC3 protein in human gastric cancer cells.

\section{Materials and methods Chemicals}

DMEM and RPMI1640 were obtained from FUJIFILM Wako Pure Chemical Industries (Osaka, Japan). Fetal bovine serum (FBS), anti-Xpress antibody (catalog number; 46-0528), SuperScript IV Reverse Transcriptase, Lipofectamine 3000, antibiotic-antimycotic and pcDNA4/His B vector were from Thermo Fisher Scientific (Waltham, MA, USA). pIRES2-AcGFP1 vector was from Takara Bio (Kusatsu, Japan). KOD-Plus DNA polymerase was from Toyobo (Osaka, Japan). SV Total RNA Isolation System was from Promega KK (Tokyo, Japan). Western Lightning ECL Pro was from PerkinElmer (Waltham, MA, USA). Anti-CLIC3 antibody (ab128941, catalog number; EPR8243), Alexa Fluor 488-conjugated anti-rabbit IgG and Alexa Fluor 568-conjugated antimouse IgG antibodies were from Abcam (Cambridge, UK). Anti- $\beta$-actin antibody (8H10D10, catalog number; 3700S) was from Cell Signaling Technology (Beverly, MA, USA). Horse-radish peroxidase-conjugated anti-rabbit and anti-mouse IgGs were from Millipore (Bedford, MA, USA). 5-Nitro-2-(3-phenylpropylamino)benzoic acid (NPPB) was from Research Biochemicals International (Natick, MA, USA). 4',6-Diamidino-2-phenylindole (DAPI) was from Dojindo Laboratories (Kumamoto, Japan). Polyethylenimine Max (PEI-Max) and Differential Quik Stain kit were from Polysciences Inc. (Warrington, PA, USA). All other reagents were of molecular biological grade or of the highest grade of purity available.

\section{Cloning of CLIC3 gene}

Total RNA was extracted from human colon cancer HT-29 cells using the SV Total RNA Isolation System, and then the cDNA was synthesized using the SuperScript IV Reverse Transcriptase according to manufacturer's instructions. The entire CLIC3 gene (accession number; NM_004669) was amplified by PCR using KODPlus DNA polymerase and the following primers (sense primer: 5'-ATCGAATTCATGGCGGAGACCAAGCTC CAGCTG-3', and anti-sense primer: $5^{\prime}$-TATTCTAGA CTAGCGGGGGTGCACGGCGGGCC- $3^{\prime}$ ). The PCR condition was 2 min at $94{ }^{\circ} \mathrm{C}$, followed by 50 cycles of $15 \mathrm{~s}$ at $94{ }^{\circ} \mathrm{C}, 30 \mathrm{~s}$ at $60{ }^{\circ} \mathrm{C}$, and $1 \mathrm{~min}$ at $68^{\circ} \mathrm{C}$. The PCR products were ligated into pcDNA4/His B (CLIC3-pcDNA4) vector equipped with Xpress-tag at the upstream of CLIC3 cDNA and pIRES2-AcGFP1 (CLIC3-pIRES2AcGFP1) vector.

\section{Cell culture and transient transfection of CLIC3}

Human embryonic kidney HEK293T cells were cultured in DMEM medium containing 10\% FBS and 1\% antibiotic-antimycotic at $37{ }^{\circ} \mathrm{C}$ in $5 \% \mathrm{CO}_{2}$. Human gastric cancer cell lines MKN7, MKN74, MKN45, KATOIII, and NUGC-4 were cultured in RPMI1640 medium containing $10 \%$ FBS and $1 \%$ antibiotic-antimycotic at $37{ }^{\circ} \mathrm{C}$ in $5 \% \mathrm{CO}_{2}$. CLIC3-pcDNA4 or CLIC3pIRES2-AcGFP1 vector was transfected into HEK293T, KATOIII, and NUGC-4 cells using PEI-Max according to manufacturer's instructions. In the CLIC3-pcDNA4 vector-transfected cells, the Xpress-attached CLIC3 protein was expressed.

CLIC3-siRNA (CGGACGUGCUGAAGGACUU) and negative control siRNA were purchased from Nippon Gene (Tokyo, Japan). Alexa 488-conjugated siRNA was obtained from Qiagen (Hilden, Germany). The siRNA (20 pmol) was transfected into MKN7 cells by using Lipofectamine 3000 in 24-well culture plate.

\section{Preparation of membrane fractions}

Cultured cells were scraped and suspended in phosphate buffered saline (PBS) containing $5 \mathrm{mM}$ EDTA. The suspension was centrifuged at $500 \times g$ for $3 \mathrm{~min}$, and the pellet was washed with PBS. After washing, cells were incubated in low ionic salt buffer $(0.5 \mathrm{mM}$ $\mathrm{MgCl}_{2}, 10 \mathrm{mM}$ Tris- $\mathrm{HCl}, \mathrm{pH} 7.4$ ) on ice for $10 \mathrm{~min}$. The cells were homogenized with Dounce homogenizer, and centrifuged at $500 \times g$ for $10 \mathrm{~min}$. Then, the supernatant was centrifuged at $100,000 \times g$ for $90 \mathrm{~min}$ at $4{ }^{\circ} \mathrm{C}$, and membrane fractions were prepared by resuspending the pellets in solution containing $250 \mathrm{mM}$ sucrose and $5 \mathrm{mM}$ Tris- $\mathrm{HCl}(\mathrm{pH} 7.4)$.

\section{Immunocytochemical analysis}

Cells were fixed with ice-cold methanol for $5 \mathrm{~min}$ at room temperature and then permeabilized with $\mathrm{PBS}$ containing $0.3 \%$ Triton $\mathrm{X}-100$ and $0.1 \%$ bovine serum albumin (BSA) for $15 \mathrm{~min}$ at room temperature. Nonspecific binding of antibodies was blocked with a solution containing $20 \mathrm{mM}$ phosphate buffer ( $\mathrm{pH}$ 7.4), $450 \mathrm{mM} \mathrm{NaCl}, 16.7 \%$ goat serum, and $0.3 \%$ Triton X-100. The cells were incubated with anti-CLIC3 $(1: 100)$ and anti-Xpress (1:100) antibodies overnight at $4{ }^{\circ} \mathrm{C}$ and then with Alexa Fluor 488-conjugated antirabbit IgG and Alexa Fluor 568-conjugated anti-mouse IgG antibodies (1:100) for $1 \mathrm{~h}$ at room temperature. DNA was visualized using DAPI (1:1,000). Immunofluorescence images were visualized by using a Zeiss LSM 780 laser scanning confocal microscope (Carl Zeiss, Oberkochen, Germany). 


\section{Electrophysiological experiments}

Whole-cell patch-clamp recordings were performed with an EPC-10 patch-clamp amplifier (HEKA Elektronik, Lambrecht, Germany). Patch master software (HEKA Elektronik) was used for command pulse control and data acquisition. Data were filtered at $2.9 \mathrm{kHz}$ and digitized at $10 \mathrm{kHz}$. The acquired data were analyzed with WinASCD software (kindly provided by Prof. G. Droogmans) and Clampfit 10.6 software (Molecular Devices, Union City, CA, USA). Patch electrodes had a resistance of 2-4 M $\Omega$ when filled with pipette solution. The access resistance was electrically compensated by $70 \%$ to minimize voltage errors. Current-voltage relationships were made from currents measured by applying voltage step pulses of $500 \mathrm{~ms}$ from -100 to $+100 \mathrm{mV}$ in $20-\mathrm{mV}$ increments or ramp pulses of $100 \mathrm{~ms}$ from -100 to $+100 \mathrm{mV}$. Steadystate currents were averaged at $450-500 \mathrm{~ms}$ on the step pulses. The currents were normalized to the corresponding membrane capacitance. HEK293T cells overexpressing human CLIC3 (24 h after transfection) and MKN7 cells were used. The CLIC3-overexpressing HEK293T cells were identified by GFP fluorescence. The pipette solution contained $140 \mathrm{mM} \mathrm{N}$-methylD-glucamine (NMDG), $14 \mathrm{mM} \mathrm{HCl}, 126 \mathrm{mM} \mathrm{L}$-aspartic acid, $2 \mathrm{mM} \mathrm{Na}{ }_{2} \mathrm{ATP}, 5 \mathrm{mM} \mathrm{MgCl}_{2}$, $10 \mathrm{mM}$ HEPES, 1 mM EGTA (pH 7.3 with Tris). The standard bathing solution contained $145 \mathrm{mM}$ NMDG, $145 \mathrm{mM} \mathrm{HCl}$, $7 \mathrm{mM} \mathrm{MgCl} 2,2 \mathrm{mM} \mathrm{CaCl}_{2}, 10 \mathrm{mM}$ HEPES (pH 7.4 with Tris). The low $\mathrm{Cl}^{-}$bathing solution contained $145 \mathrm{mM}$ NMDG, $145 \mathrm{mM} \mathrm{L}$-aspartic acid, $7 \mathrm{mM} \mathrm{MgCl} 2,2 \mathrm{mM}$ $\mathrm{CaCl}_{2}, 10 \mathrm{mM}$ HEPES (pH 7.4 with Tris).

\section{Tissue microarray (TMA) analysis}

Tumor specimens from 107 patients with gastric cancer who underwent a surgery at Toyama University Hospital from 2001 to 2008 were used (Additional file 1: Table S1 and Additional file 2: Fig. S1). The tumors were histologically diagnosed in the Department of Pathology, University of Toyama. The final stage of gastric cancer was confirmed pathologically according to the TNM Classification of Malignant Tumors, 8th edition. The ethics committee of the University of Toyama approved this study.

The TMA comprised 1.0-mm cores of tissues from the paraffin-embedded blocks of the surgical specimen described above. Paraffin blocks containing tumor tissue were selected, and the representative areas encompassing the tumors were marked directly on the blocks according to the corresponding hematoxylin-eosin (HE)-stained slides. The array block was cut into sections that were placed onto glass slides for HE staining and immunohistochemical analyses. The sections were treated with an anti-CLIC3 antibody at a dilution of 1:50.

The expression level of CLIC3 was evaluated from distribution of staining and its intensity in each section. Distribution of CLIC3 staining in the section was scored as 0 ( $0 \%$ of total area), $1(1-50 \%)$ and $2(51-100 \%)$. Intensity of CLIC3 staining was scored as 0 (absent), 1 (weak), 2 (moderate) and 3 (strong). We defined that the tissue section is "CLIC3-high" if sum of two scores was 3 and above. Two researchers who do not know clinicopathological information of patients independently evaluated the section.

\section{Western blotting}

Membrane proteins $(30 \mu \mathrm{g})$ were treated with $2 \%$ sodium dodecyl sulfate (SDS) plus 5\% $\beta$-mercaptoethanol, and they were separated by electrophoresis on SDS-polyacrylamide gels, and transferred to PVDF membranes. Non-specific binding of antibodies was blocked with $5 \%$ non-fat milk. The membranes were incubated with anti-CLIC3 (1:1000), anti-Xpress (1:5000), and anti- $\beta$-actin antibodies (1:5000) overnight at $4{ }^{\circ} \mathrm{C}$. HRP-conjugated anti-rabbit IgG and anti-mouse IgG antibodies were used as secondary antibodies (1:5000). The signals were visualized using Western Lightning ECL Pro. To quantify the chemiluminescence signals on the membranes, a FujiFilm's LAS-4000 system and MultiGauge software (FujiFilm) were used.

Full images of the PVDF membranes obtained from Western blotting experiments are shown in Additional file 3: Fig. S2.

\section{Cell proliferation assay}

In 24-well culture plate, KATOIII cells $\left(9 \times 10^{3}\right.$ cells per well) and NUGC-4 cells $\left(6 \times 10^{3}\right.$ cells per well $)$ were transfected with CLIC3-pIRES2-AcGFP1 vector or pIRES2-AcGFP1 vector (mock). Total cell numbers in each well were counted on transfection (1st counting) and $48 \mathrm{~h}$ after transfection (2nd counting). We confirmed that cell density for gene transfection (1st counting) has been in similar values between mock transfection and CLIC3 gene transfection (KATOIII cells, $9 \times 10^{3}$ cells; NUGC-4 cells, $6 \times 10^{3}$ cells). Cell proliferation was defined as an increased cell numbers between 1st and 2nd countings.

The siRNA-transfected MKN7 cells were plated on 24-well culture plate. After 24-h culture, the cells were dissociated and replated on 24-well culture plate $\left(1.5 \times 10^{4}\right.$ cells per well). Total cell numbers in each well were counted at $48 \mathrm{~h}$ after the replating.

\section{Transwell migration assay and invasion assay}

The protocol for analyzing in vitro cell migration was based on a transwell migration assay (Boyden chamber 
assay). Falcon cell culture inserts (Corning, Corning, NY, USA) with porous membranes (pore-size $8 \mu \mathrm{m})$ were placed into a 24 -well plate. The attractant (medium containing 10\% FBS) was added to the lower chamber, and KATOIII or NUGC- 4 cells $\left(4.0 \times 10^{4}\right.$ cells) were suspended in serum-free medium and added to the upper chamber. The cells were incubated at $37^{\circ} \mathrm{C}$ for $72 \mathrm{~h}$. The migrated cells attached to the lower side of the membrane were fixed and stained using a Differential Quik Stain kit. Cells remaining on the upper side of membrane were removed with a cotton swab. The membranes containing the migrated cells were dried, and the cells were counted in three randomly selected fields $(\times 200)$.

Cell invasion was assessed by using a Matrigel transwell invasion assay. Cell culture inserts with porous membranes (pore-size $8 \mu \mathrm{m}$ ) were coated overnight with $0.5 \mathrm{mg} / \mathrm{ml}$ Matrigel (Corning). The inserts were placed into a 24-well plate and the attractant (medium containing $10 \%$ FBS) was added to the lower chamber, and KATOIII cells $\left(4.0 \times 10^{4}\right.$ cells) were suspended in serumfree medium and added to the upper chamber. The cells were incubated at $37{ }^{\circ} \mathrm{C}$ for $72 \mathrm{~h}$. The invaded cells attached to the lower side of the membrane were fixed, stained and counted.

\section{Statistical analysis}

Data are expressed as the mean \pm SEM. Differences between groups were analyzed by Chi-square test, Fisher's exact test and $t$-test. Overall survival and diseasespecific survival were analyzed using the Kaplan-Meier method and the log-rank test. Statistical analysis was performed using JMP Pro 13.0.0 (SAS institute., Cary, $\mathrm{NC}$, USA) and $p$ values $<0.05$ were considered to be significant.

\section{Results}

\section{Expression of CLIC3 in human gastric cancer cells}

In a TMA of gastric cancer (107 specimens) treated with the anti-CLIC3 antibody, significant expression of CLIC3 protein ("CLIC3-high"; see Materials and methods) was found in 49 specimens (Fig. 1a, b, and Table 1). In the specimens judged as "CLIC3-high", CLIC3 protein was localized in both the plasma membrane and intracellular compartment of cancer cells (Fig. 1b). In the CLIC3high samples, expression level of CLIC3 in the cancer tissue was comparable to that of adjacent non-cancer tissue (Fig. 1c, left). In the "CLIC3-low" samples, however, expression level of CLIC3 in the cancer tissue was much lower than non-cancer tissue (Fig. 1b, c, right).

In Fig. 1d, expression levels of CLIC3 in membrane fractions of human gastric cancer cell lines were examined. CLIC3 was detected in MKN7 cells, while no significant signal of CLIC3 was observed in MKN74, MKN45, KATOIII, and NUGC-4 cells (Fig. 1d). In immunocytochemistry of MKN7 cells, endogenous CLIC3 was found to be expressed partly in the plasma membrane as well as intracellular compartment (Fig. 1e).

\section{Effects of CLIC3 expression on prognosis of gastric cancer patients}

Correlation between expression level of CLIC3 and various prognostic factors is summarized in Table 1. Unexpectedly, expression level of CLIC3 was negatively correlated with pathological tumor depth: that is, the CLIC3-low samples showed deeper depth compared to the CLIC3-high samples. On the other hand, CLIC3 expression was not significantly related to gender, age, lymph node metastasis, liver metastasis, peritoneal dissemination, distant metastasis, peritoneal lavage cytology, pathological stage, histology, lymphatic invasion, and venous invasion (Table 1). Corresponding to above results, Kaplan-Meier survival curves showed that expression level of CLIC3 was negatively correlated with overall survival (Fig. 2a) and disease-specific survival (Fig. 2b): that is, the CLIC3-low patients showed poorer survival rate compared to the CLIC3-high patients. These results suggest that decreased expression of CLIC3 in gastric cancer may result in poor prognosis of the patients.

\section{Electrophysiology in the CLIC3-expressing cells}

To clarify electrophysiological properties of CLIC3, it was exogenously expressed in HEK293T cells. A single band of CLIC3 was found in membrane samples of CLIC3 (CLIC3-pcDNA4 vector)-expressing cells, but not of empty vector-transfected (mock) cells by using anti-CLIC3 and anti-Xpress antibodies (Fig. 3a). In immunocytochemistry of the CLIC3-expressing HEK293T cells, CLIC3 was expressed partly in the plasma membrane as well as intracellular compartments (Fig. 3b). In whole-cell patch-clamp recordings, a significant outwardly rectifying $\mathrm{Cl}^{-}$current was observed in CLIC3-expressing cells, but not in mock cells (Fig. 3c, d). As expected, the reversal potential of the current was positively shifted by a decrease in extracellular $\mathrm{Cl}^{-}$concentration (Fig. 3e). The reversal potentials of the currents obtained by applying ramp pulses from $-100 \mathrm{mV}$ to $100 \mathrm{mV}$ under control and low $\mathrm{Cl}^{-}$conditions were $-26.6 \pm 4.2$ and $-3.7 \pm 2.1 \mathrm{mV}$ $(n=3)$, respectively (Additional file 4: Fig. S3). NPPB, a $\mathrm{Cl}^{-}$channel blocker, significantly decreased the currents (Fig. 3f). In gastric cancer MKN7 cells endogenously expressing CLIC3, similar $\mathrm{Cl}^{-}$currents were observed (Fig. 3g). Expectedly, the currents were sensitive to NPPB. These results suggest that exogenous and 


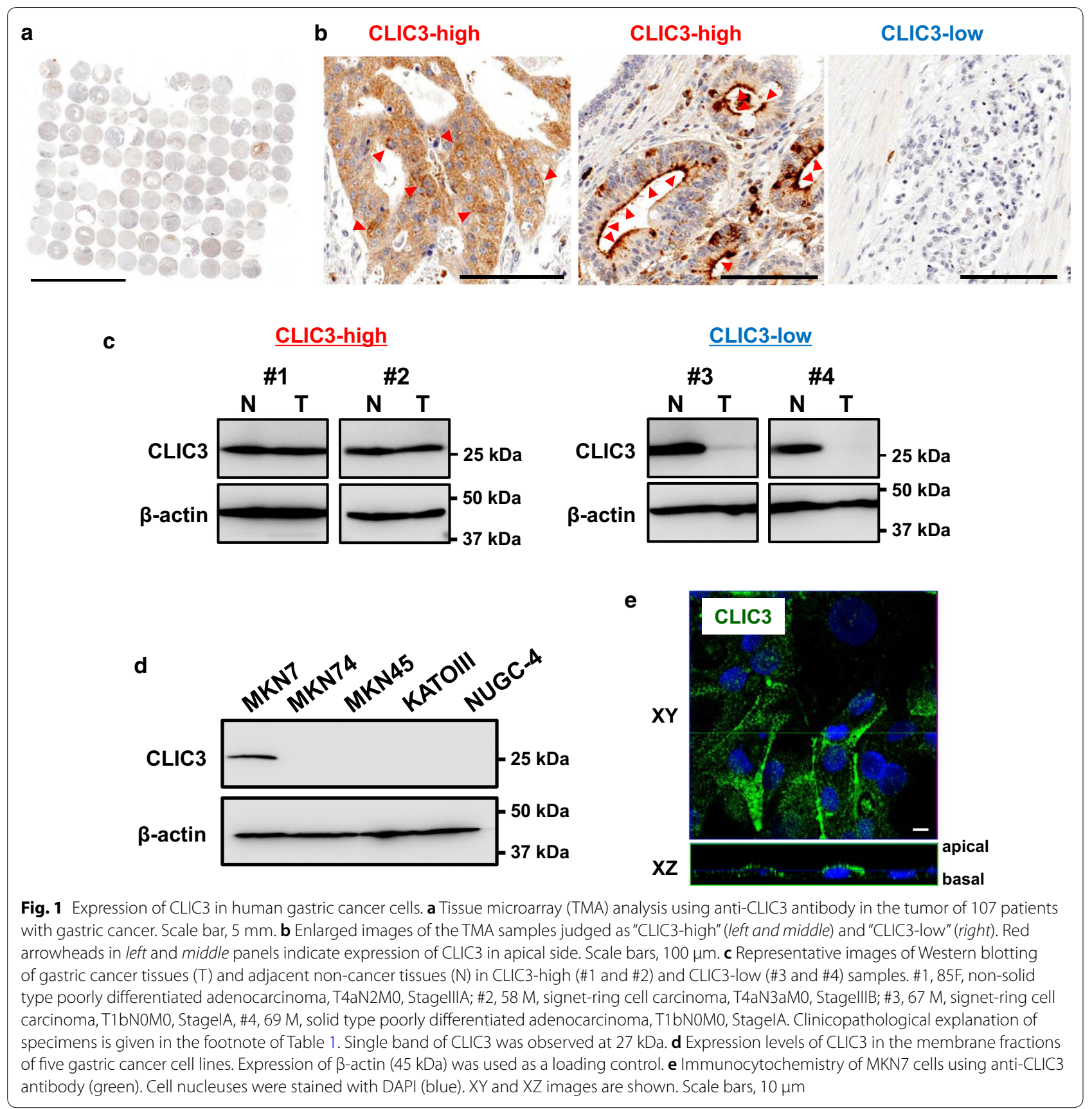

endogenous CLIC3 proteins function as outwardly rectifying $\mathrm{Cl}^{-}$channels in the plasma membrane.

\section{Knockdown of CLIC3 accelerated cell proliferation in MKN7 cells}

Expression level of CLIC3 was found to be negatively correlated with pathological tumor depth (Table 1). Since tumor proliferation is associated with tumor depth, we examined effects of CLIC3 expression on cancer cell proliferation. CLIC3 was knocked down in MKN7 cells by using siRNA for CLIC3. Transfection efficiency was evaluated with fluorescence of Alexa 488-conjugated siRNA. Almost all the cells showed significant fluorescence (Fig. 4a). The expression level of CLIC3 protein was confirmed to be decreased dramatically in CLIC3 siRNA-transfected MKN7 cells compared with negative control siRNA-transfected cells (Fig. 4b). Interestingly, the increased cell number in CLIC3 siRNA-transfected 
Table 1 Relationship between expression of CLIC3 and clinicopathological characteristics of patients with gastric cancer

\begin{tabular}{|c|c|c|c|}
\hline & $\begin{array}{l}\text { CLIC3-high } \\
(n=49)\end{array}$ & $\begin{array}{l}\text { CLIC3-low } \\
(n=58)\end{array}$ & $p$-value \\
\hline \multicolumn{4}{|l|}{ Gender } \\
\hline Male & 32 & 41 & \multirow[t]{2}{*}{0.5516} \\
\hline Female & 17 & 17 & \\
\hline \multicolumn{4}{|l|}{ Age } \\
\hline$\geq 65$ & 35 & 39 & \multirow[t]{2}{*}{0.6399} \\
\hline$<65$ & 14 & 19 & \\
\hline \multicolumn{4}{|l|}{ pT } \\
\hline T1a-T2 & 17 & 10 & \multirow[t]{2}{*}{$0.0381^{*}$} \\
\hline T3-T4b & 32 & 48 & \\
\hline \multicolumn{4}{|l|}{$\mathrm{pN}$} \\
\hline NO & 15 & 17 & \multirow[t]{2}{*}{0.8835} \\
\hline $\mathrm{N} 1-3$ & 34 & 41 & \\
\hline \multicolumn{4}{|l|}{ H } \\
\hline $\mathrm{HO}$ & 47 & 54 & \multirow[t]{2}{*}{0.5234} \\
\hline $\mathrm{H} 1$ & 2 & 4 & \\
\hline \multicolumn{4}{|l|}{$P$} \\
\hline PO & 44 & 55 & \multirow[t]{2}{*}{0.3241} \\
\hline P1 & 5 & 3 & \\
\hline \multicolumn{4}{|l|}{ M } \\
\hline Mo & 37 & 41 & \multirow[t]{2}{*}{0.5754} \\
\hline M1 & 12 & 17 & \\
\hline \multicolumn{4}{|l|}{ CY } \\
\hline CYO & 43 & 48 & \multirow[t]{2}{*}{0.4676} \\
\hline $\mathrm{CY} 1$ & 6 & 10 & \\
\hline \multicolumn{4}{|l|}{ pStage } \\
\hline$|A-| \mid B$ & 26 & 22 & \multirow[t]{2}{*}{0.1165} \\
\hline IIIA-IV & 23 & 36 & \\
\hline \multicolumn{4}{|l|}{ Histology } \\
\hline pap/tub1/tub2 & 17 & 30 & \multirow[t]{2}{*}{0.0913} \\
\hline por1/por2/sig/muc & 31 & 28 & \\
\hline \multicolumn{4}{|l|}{ ly } \\
\hline- & 8 & 7 & \multirow[t]{2}{*}{0.5282} \\
\hline+ & 41 & 51 & \\
\hline \multicolumn{4}{|l|}{ v } \\
\hline- & 11 & 14 & \multirow[t]{2}{*}{0.8369} \\
\hline+ & 38 & 44 & \\
\hline
\end{tabular}

pT pathological tumor depth, T1a tumor invades lamina propria or muscularis mucosae, $T 1 b$ tumor invades submucosa, $T 2$ tumor invades muscularis propria, T3 tumor invades subserosa, T4a tumor perforates serosa, $T 4 b$ tumor invades adjacent structures, $p N$ pathological lymph node metastasis, NO no regional lymph node metastasis, $N 1$ metastasis in 1 to 2 regional lymph nodes, N2 metastasis in 3 to 6 regional lymph nodes, $N 3$ metastasis in 7 or more regional lymph nodes, $\mathrm{H}$ liver metastasis; $\mathrm{HO}$ no liver metastasis, $\mathrm{H} 1$ liver metastasis, $P$ peritoneal dissemination, $P O$ no peritoneal dissemination, $P 1$ peritoneal disseminationm, $M$ distant metastasis, $M O$ no distant metastasis, $M 1$ distant metastasis, $C Y$ peritoneal lavage cytology, $C Y O$ no peritoneal lavage cytology, $C Y 1$ peritoneal lavage cytology, $p$ Stage pathological stage (TNM stage), StagelA T1NOMO, StagelB T1N1M0 or T2NOMO, StagellA T1N2M0 or T2N1M0 or T3NOMO, StagellB T1N3aM0 or T2N2M0 or T3N1M0 or T4aN0M0, StagellIA T2N3aM0 or T3N2M0 or T4aN1M0 or T4aN2M0 or T4bN0M0, StagellIB T1 N3bM0 or T2N3bM0 or T3N3aM0 or T4aN3aM0 or T4bN1M0 or T4bN2M0, StagellIC T3N3bM0 or T4aN3bM0 or T4bN3aM0 or T4bN3bM0, StagelV anyTanyNM1. Histology, pap
Table 1 (continued)

papillary adenocarcinoma, tub1 well differentiated tubular adenocarcinoma, tub2 moderately differentiated tubular adenocarcinoma, por1 solid type poorly differentiated adenocarcinoma, por2 non-solid type poorly differentiated adenocarcinoma, sig signet-ring cell carcinoma, muc mucinous adenocarcinoma, ly lymphatic invasion, ly $(-)$ no lymphatic invasion, ly $(+)$ lymphatic invasion, $v$ venous invasion, $v(-)$ no venous invasion, $v(+)$ venous invasion
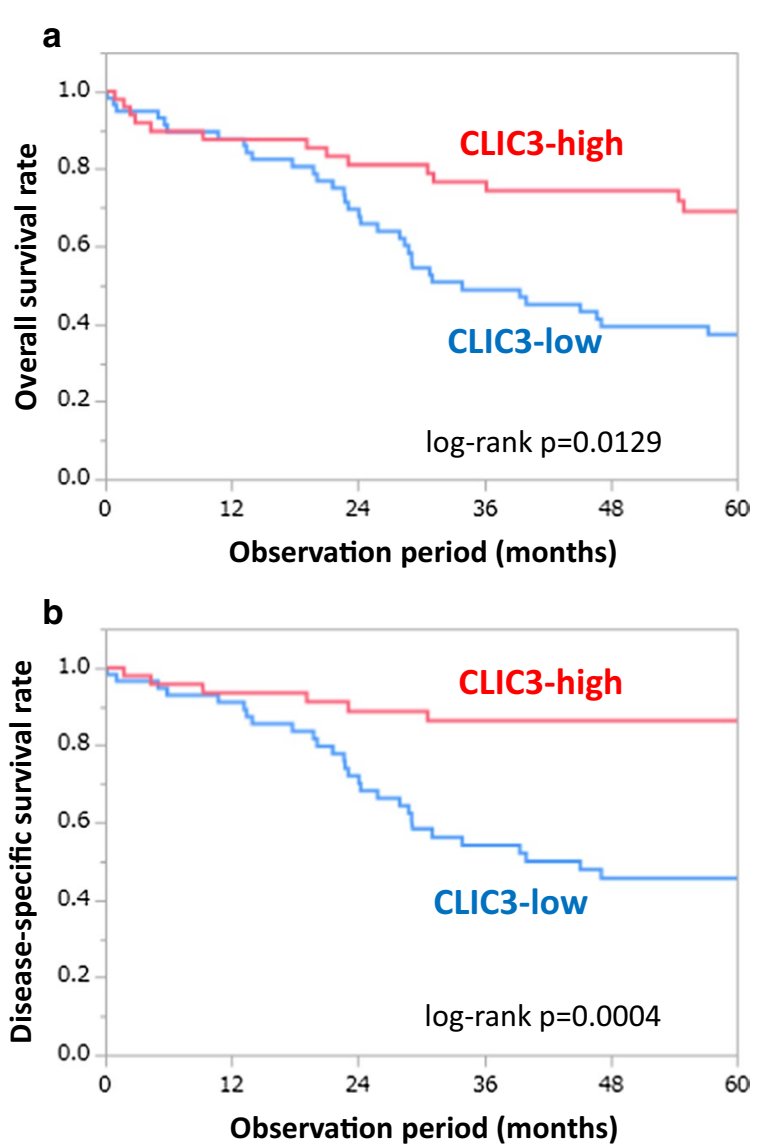

Fig. 2 Effects of CLIC3 expression on prognosis of gastric cancer patients. a Correlation between expression level of CLIC3 and overall survival. b Disease-specific survival after surgery. They were analyzed by performing Kaplan-Meier survival analysis (log-rank test)

MKN7 cells was significantly greater than that in negative control siRNA-transfected cells (Fig. 4c).

\section{Overexpression of CLIC3 attenuated cell proliferation in human gastric cancer KATOIII and NUGC-4 cells} Next, CLIC3 was overexpressed in KATOIII and NUGC-4 cells in which endogenous expression of CLIC3 is negligible (Fig. 5a). After transfection, almost all the cells showed significant fluorescence of CLIC3, indicating high efficiency of the transfection (Fig. 5b). The increased cell number of KATOIII and NUGC-4 cells expressing CLIC3 was significantly lower than their mock cells (Fig. 5c). 


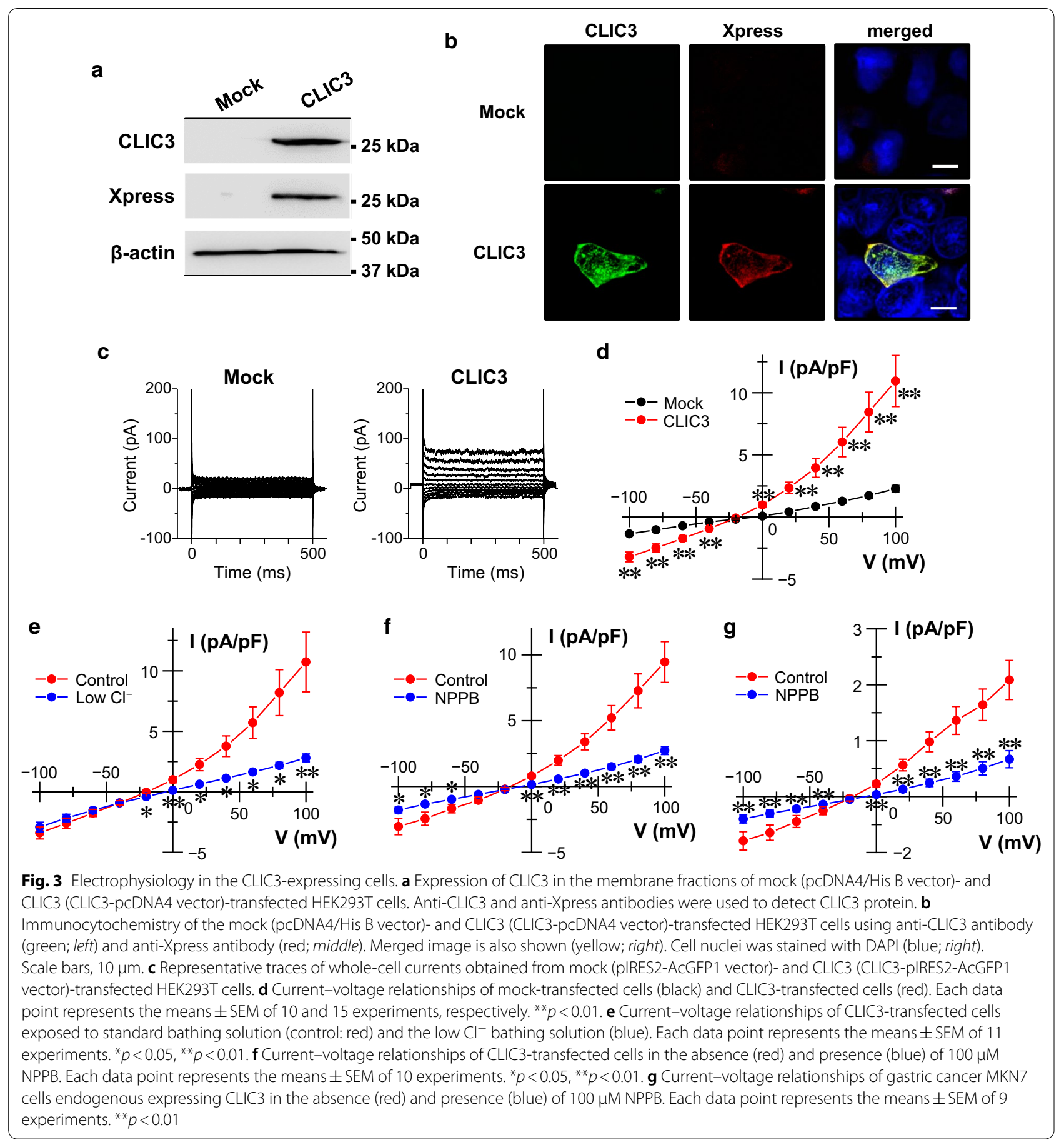

\section{No effects of CLIC3 overexpression on migration} and invasion of KATOIII cells

Next we investigated abilities of migration and invasion of gastric cancer KATOIII cells transfected with an empty vector (mock) or a CLIC3 expression vector using a transwell (Fig. 6a). Consistent with results in Table 1, overexpression of CLIC3 had no significant effects on migration (Fig. 6b) and invasion (Fig. 6c) of the gastric cancer cells. 
a

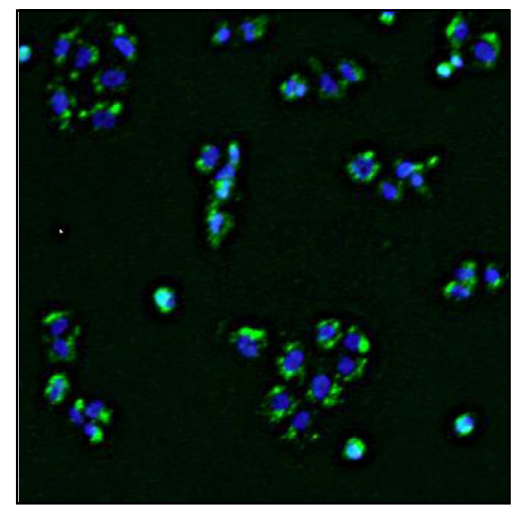

b

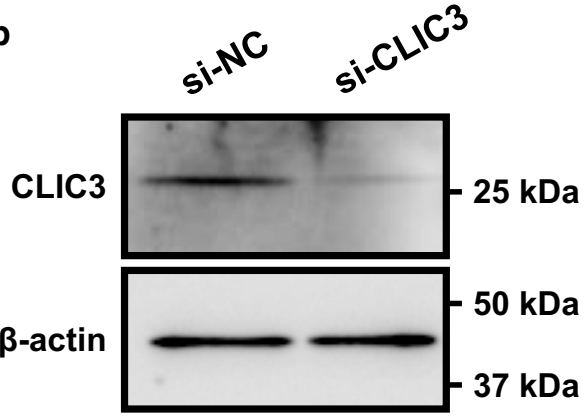

C

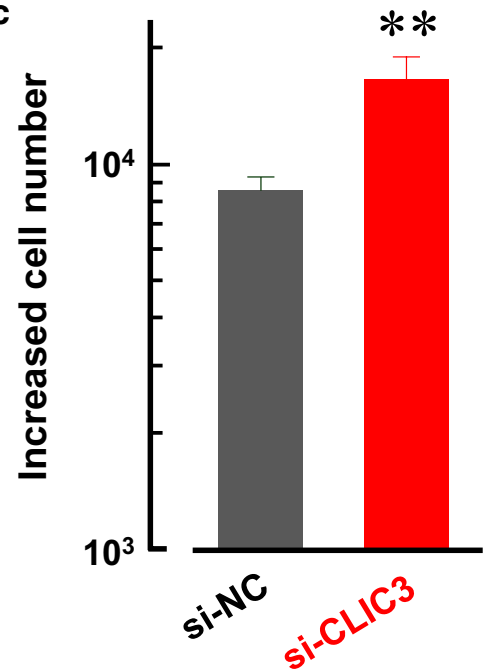

Fig. 4 Knockdown of CLIC3 accelerated cell proliferation in MKN7 cells. a Transfection of Alexa 488-conjugated siRNA in MKN7 cells. b Expression level of CLIC3 in MKN7 cells transfected with negative control siRNA (si-NC) and CLIC3 siRNA (si-CLIC3). Anti-CLIC3 antibody was used to detect CLIC3 protein. Expression of $\beta$-actin ( $45 \mathrm{kDa}$ ) was used as a loading control. c Effects of CLIC 3 expression on cell proliferation of MKN7 cells. Increased cell numbers at $48 \mathrm{~h}$ after replating are shown. Five independent experiments were performed. The bars represent the means \pm SEM. ${ }^{* *} p<0.01$

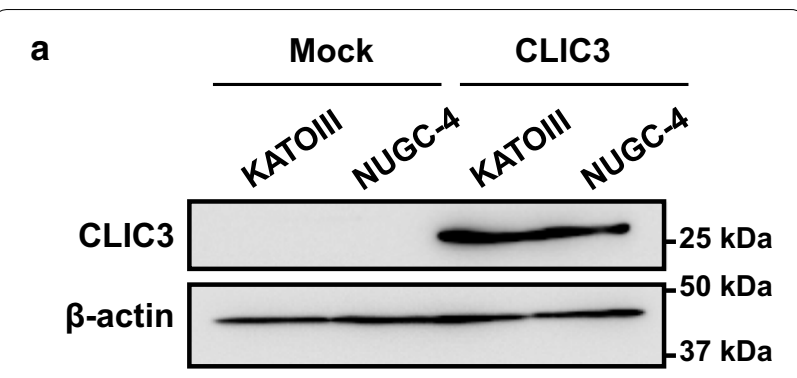

b

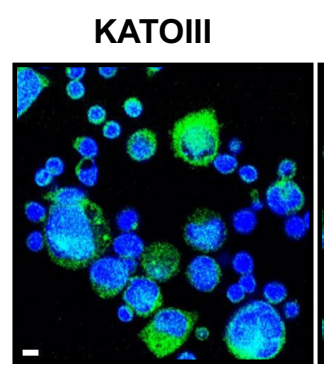

NUGC-4

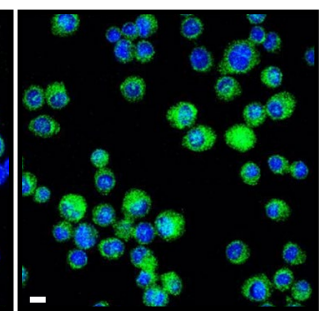

C

KATOIII

NUGC-4
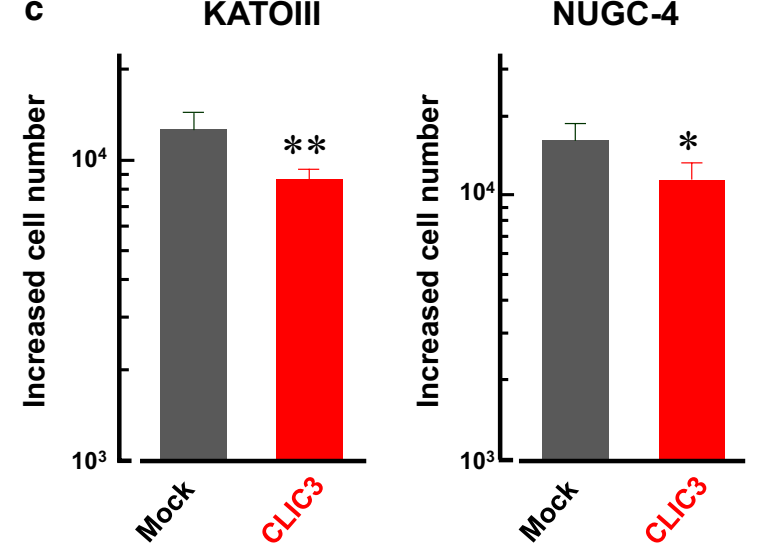

Fig. 5 Overexpression of CLIC3 attenuated cell proliferation in KATOIII and NUGC-4 cells. a Expression level of CLIC3 in the membrane fractions of mock- and CLIC3-transfected KATOIII and NUGC-4 cells. Anti-CLIC3 antibody was used to detect CLIC3 protein (27 kDa). b Immunocytochemistry of KATOIII (left) and NUGC-4 cells (right) transfected with CLIC3 using anti-CLIC3 antibody (green). Cell nucleuses were stained with DAPI (blue). Scale bars, $10 \mu \mathrm{m}$. c Effects of CLIC3 expression on cell proliferation of KATOIII (left) and NUGC-4 cells (right). Increased cell numbers between 1st and 2nd countings (see Methods) are shown. Experiments were performed in triplicate. The bars represent the means \pm SEM. ${ }^{*} p<0.05,{ }^{* *} p<0.01$

\section{Discussion}

CLIC3 protein behaves as not only a soluble protein, but also an organellar membrane protein [10-12]. As a soluble protein, secreted CLIC3 promotes angiogenesis and invasion of ovarian cancer cells and breast 


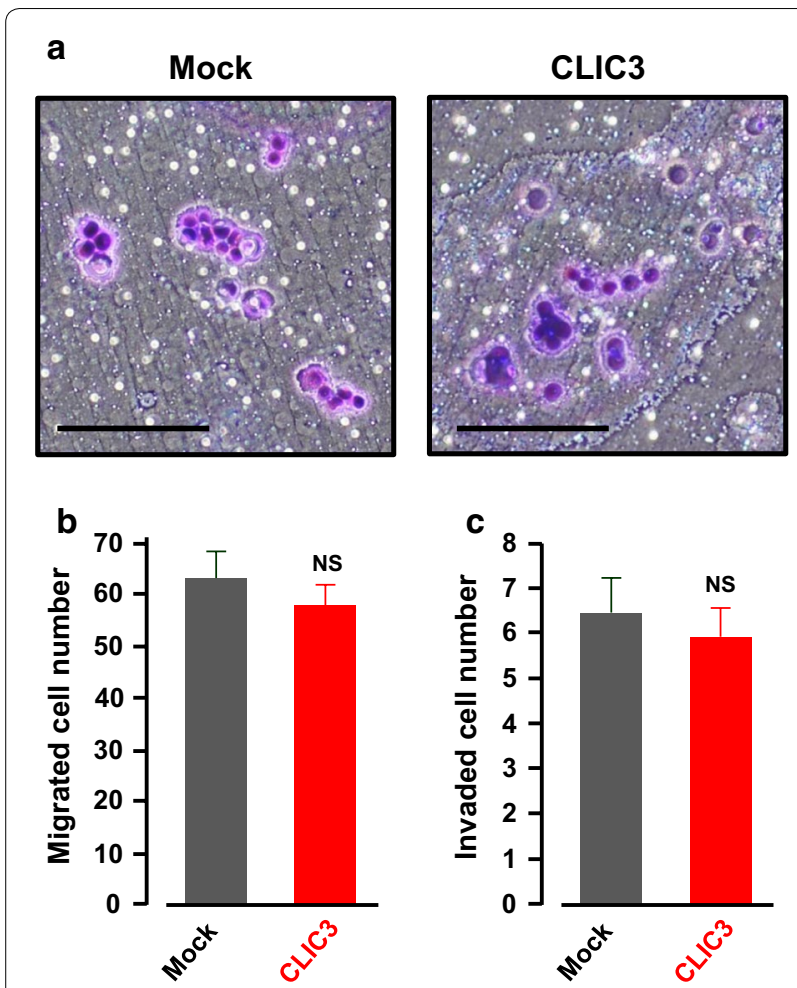

Fig. 6 Transwell migration and invasion assay. a Morphology of mock- and CLIC3-transfected KATOIII cells. The migrating cells were stained with violet color. Scale bar, $100 \mu \mathrm{m}$. b Effects of CLIC3 expression on migration of the KATOIII cells. Migrated cell number in three different fields (each field $=400 \times 400 \mu \mathrm{m}$ ) were counted in the experiment and the values were averaged. Three independent experiments were performed. The bars represent the means \pm SEM. NS, not significant $(p>0.05)$. c Effects of CLIC3 expression on invasion of the KATOIII cells. Invaded cell number in three different fields (each field $=800 \times 800 \mu \mathrm{m}$ ) were counted in the experiment and the values were averaged. Nine independent experiments were performed. The bars represent the means \pm SEM. NS, not significant $(p>0.05)$

cancer cells both in vivo and in 3D cell culture models by reducing transglutaminase-2 [16]. As an organellar membrane protein, CLIC3 in late endosome and lysosome promotes migration and invasion of pancreatic ductal adenocarcinoma by recycling integrins [13], and it also dictates invasion and metastasis of breast cancer by controlling recycling of late endosomal membranetype matrix metalloproteinase-1 (MT1-MMP) [15]. These reports suggest that both soluble and organellar CLIC3 is associated with poor prognosis in cancers.

In the present study, the TMA analysis of patients with gastric cancer who underwent a surgery showed that expression level of CLIC3 was negatively correlated with overall survival and disease-specific survival (Fig. 2). It is noted that the relationship between expression level of CLIC3 and prognosis were opposite to the previous reports [13-17], although the types of cancer are different. In fact, expression level of CLIC3 was negatively correlated with pathological tumor depth (Table 1). Generally, tumor depth is associated with the proliferative capacity [18]. Our present results showed that cell proliferation was significantly enhanced by knockdown of CLIC3 in MKN7 cells, and that the proliferation was inhibited by exogenous CLIC3 expression in KATOIII and NUGC-4 cells in which endogenous CLIC3 expression is negligible (Figs. 1 and 5). These results suggest that decreased expression of CLIC3 stimulates their malignant potential in gastric cancer. On the other hand, metastatic potential is generally associated with the invasive and migratory capacity $[19,20]$. In the present study, however, migration and invasion of cancer cells are not affected by exogenous CLIC3 expression in the gastric cancer cells.

Here, we also found that CLIC3 was partially expressed in the plasma membrane of gastric cancer cells in CLIC3high patients and MKN7 cells. To our knowledge, it is the first report showing that CLIC3 is localized in the plasma membrane of cancer cells in human tissues. In fact, our patch-clamp experiments showed that both exogenous and endogenous CLIC3 function as outwardly rectifying $\mathrm{Cl}^{-}$channels. In the present study, CLIC3 currents exhibited the reversal potentials at around $-27 \mathrm{mV}$. This value is shallower than the estimated equilibrium potential for $\mathrm{Cl}^{-}$of $-48 \mathrm{mV}$. If it is assumed that aspartate ion partially permeates through CLIC3, the permeability of aspartate ion to $\mathrm{Cl}^{-}$was calculated to be $0.34 \pm 0.07$ $(n=3)$ based on the reversal potential shift obtained from the ramp pulse experiments (Additional file 4: Fig. S3).

The activities of $\mathrm{Cl}^{-}$channels in the plasma membrane are responsible for intracellular $\mathrm{Cl}^{-}$homeostasis. So far, a close association between intracellular $\mathrm{Cl}^{-}$concentration $\left(\left[\mathrm{Cl}^{-}\right]_{i}\right)$ and cancer cell proliferation has been reported. Gastric cancer MKN28 cells cultured in a low $\mathrm{Cl}^{-}$medium exhibit a decrease in $\left[\mathrm{Cl}^{-}\right]_{i}$ and reduced cell proliferation with $\mathrm{G} 0 / \mathrm{G} 1$ arrest [21]. Interestingly, $\left[\mathrm{Cl}^{-}\right]_{i}$ affects the anti-cancer activity of paclitaxel, a microtubule-targeted chemotherapeutic drug, in MKN28 cells [22]. A decrease in $\left[\mathrm{Cl}^{-}\right]_{i}$ also attenuates cell proliferation of prostate cancer PC3 cells [23]. Changes in expression level of CLIC3 in the plasma membrane may disrupt intracellular $\mathrm{Cl}^{-}$homeostasis in gastric cancer cells, resulting in the enhancement of cancer cell growth. Thus, the plasma membrane expression of gastric CLIC3 may explain why CLIC3 function in gastric cancers is different from other cancers. Future study is necessary to clarify the mechanism of regulation of CLIC3 expression in gastric cancer cells. 


\section{Conclusions}

Our study clarifies that CLIC3 has a channel activity in the plasma membrane of gastric cancer cells, and that decreased expression of CLIC3 results in unfavorable prognosis of gastric cancer patients via stimulation of the cancer cell proliferation. These findings suggest that pathophysiological role of CLIC3 in plasma membrane is different from that in cytosol and organellar membrane of the cancer cells.

\section{Supplementary information}

Supplementary information accompanies this paper at https://doi. org/10.1186/s12576-020-00740-7.

Additional file 1: Table S1. Expression of CLIC3 and clinicopathological characteristics patients with gastric cancer.

Additional file 2: Fig. S1. Enlarged image of tissue microarray analysis (Fig. 1a) and the specimen numbers.

Additional file 3: Fig. S2. Full images of Western blotting shown in Fig. 1C (a), Figs. $1 \mathrm{~d}$ and $3 \mathrm{a}$ (b) and Figs. $4 \mathrm{~b}$ and $5 \mathrm{a}$ (c).

Additional file 4: Fig. S3. Representative current-voltage relationships of CLIC3 currents recorded with ramp pulses $(100 \mathrm{~ms})$ from $-100 \mathrm{mV}$ to $+100 \mathrm{mV}$ in the CLIC3-expressing HEK293T cells exposed to standard bathing solution (control: red) and the low $\mathrm{Cl}^{-}$bathing solution (blue).

\section{Abbreviations}

CLIC: Chloride intracellular channel; DAPI: 4',6-Diamidino-2-phenylindole; FBS:

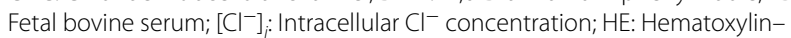
eosin; NPPB: 5-Nitro-2-(3-phenylpropylamino)benzoic acid; PBS: Phosphate buffered saline; PEI-Max: Polyethylenimine Max; TMA: Tissue microarray.

\section{Acknowledgements}

This work was supported by Grants-in-Aid for Scientific Research (KAKENHI) from Japan Society for the Promotion of Science (JSPS) (to H.S. (JP15K15029), Ta.F. (JP26460291 and JP17K08531) and T.S. (JP16K08490)), and by JSPS Coreto-Core Program, B. Asia-Africa Science Platforms.

\section{Authors' contributions}

SK, TaF, TS, TO, TN, TsF and HS designed the study and wrote the manuscript. $\mathrm{SK}, \mathrm{TaF}, \mathrm{TS}, \mathrm{KS}, \mathrm{IH}$ performed the experiments. All authors reviewed the results of the manuscript. All authors read and approved the final manuscript.

\section{Funding}

No fund was received for this study.

\section{Availability of data and materials}

Not applicable.

\section{Ethics approval and consent to participate}

All procedures performed in studies involving human participants were in accordance with the ethical standards of the institutional and/or national research committee and with the 1964 Helsinki Declaration and its later amendments or comparable ethical standards. Ethics Committee of University of Toyama (Protocol no. 29-85) approved this study.

\section{Informed consent}

Informed consent was obtained from all individual participants included in the study.

\section{Competing interests}

The authors declare that they have no competing interests.

\section{Author details}

1 Department of Surgery and Sciences, Graduate School of Medicine and Pharmaceutical Sciences, University of Toyama, Toyama 930-0194, Japan.

2 Department of Pharmaceutical Physiology, Graduate School of Medicine and Pharmaceutical Sciences, University of Toyama, 2630 Sugitani, Toyama 930-0194, Japan.

Received: 7 September 2019 Accepted: 4 February 2020

Published online: 17 February 2020

\section{References}

1. Torre LA, Bray F, Siegel RL, Ferlay J, Lortet-Tieulent J, Jemal A (2015) Global cancer statistics 2012. CA Cancer J Clin 65:87-108

2. Bray F, Ren JS, Masuyer E, Ferlay J (2013) Global estimates of cancer prevalence for 27 sites in the adult population in 2008. Int J Cancer 132:1133-1145

3. Asoglu O, Matlim T, Kurt A, Onder SY, Kunduz E, Karanlik H, Sam B, Kapran Y, Bugra D (2013) Guidelines for extended lymphadenectomy in gastric cancer: a prospective comparative study. Ann Surg Oncol 20:218-225

4. Lee Jl, Kim JH, Kim JH, Choi BJ, Song YJ, Choi SB, Bae YS, Lee SH, Jee SR, Kang MS, Seol SY (2012) Indication for endoscopic treatment of ulcerative early gastric cancer according to depth of ulcer and morphological change. J Gastroenterol Hepatol 27:1718-1725

5. Koizumi W, Kim YH, Fujii M, Kim HK, Imamura H, Lee KH, Hara T, Chung HC, Satoh T, Cho JY, Hosaka H, Tsuji A, Takagane A, Inokuchi M, Tanabe K, Okuno T, Ogura M, Yoshida K, Takeuchi M, Nakajima T, JACCRO, and KCSG Study Group (2014) Addition of docetaxel to S-1 without platinum prolongs survival of patients with advanced gastric cancer: a randomized study (START). J Cancer Res Clin Oncol 140:319-328

6. Nashimoto A, Akazawa K, Isobe Y, Miyashiro I, Katai H, Kodera Y, Tsujitani S, Seto Y, Furukawa H, Oda I, Ono H, Tanabe S, Kaminishi M (2013) Gastric cancer treated in 2002 in Japan: 2009 annual report of the JGCA nationwide registry. Gastric Cancer 16:1-27

7. Peng J, Chen W, Chen J, Yuan Y, Zhang J, He Y (2018) Overexpression of chloride channel-3 predicts unfavorable prognosis and promotes cellular invasion in gastric cancer. Cancer Manag Res 10:1163-1175

8. Liu F, Cao QH, Lu DJ, Luo B, Lu XF, Luo RC, Wang XG (2015) TMEM16A overexpression contributes to tumor invasion and poor prognosis of human gastric cancer through TGF- $\beta$ signaling. Oncotarget 6:11585-11599

9. Chen CD, Wang CS, Huang YH, Chien KY, Liang Y, Chen WJ, Lin KH (2007) Overexpression of CLIC1 in human gastric carcinoma and its clinicopathological significance. Proteomics 7:155-167

10. Littler DR, Brown LJ, Breit SN, Perrakis A, Curmi PM (2010) Structure of human CLIC3 at $2 \AA$ A resolution. Proteins 78:1594-1600

11. Qian Z, Okuhara D, Abe MK, Rosner MR (1999) Molecular cloning and characterization of a mitogen-activated protein kinase-associated intracellular chloride channel. J Biol Chem 274:1621-1627

12. Money TT, King RG, Wong MH, Stevenson JL, Kalionis B, Erwich JJ, Huisman MA, Timmer A, Hiden U, Desoye G, Gude NM (2007) Expression and cellular localisation of chloride intracellular channel 3 in human placenta and fetal membranes. Placenta 28:429-436

13. Dozynkiewicz MA, Jamieson NB, Macpherson I, Grindlay J, van den Berghe PV, von Thun A, Morton JP, Gourley C, Timpson P, Nixon C, McKay CJ, Carter R, Strachan D, Anderson K, Sansom OJ, Caswell PT, Norman JC (2012) Rab25 and CLIC3 collaborate to promote integrin recycling from late endosomes/lysosomes and drive cancer progression. Dev Cell 22:131-145

14. Hu D, Ansari D, Pawłowski K, Zhou Q, Sasor A, Welinder C, Kristl T, Bauden M, Rezeli M, Jiang Y, Marko-Varga G, Andersson R (2018) Proteomic analyses identify prognostic biomarkers for pancreatic ductal adenocarcinoma. Oncotarget 9:9789-9807

15. Macpherson IR, Rainero E, Mitchell LE, van den Berghe PV, Speirs C, Dozynkiewicz MA, Chaudhary S, Kalna G, Edwards J, Timpson P, Norman JC (2014) CLIC3 controls recycling of late endosomal MT1-MMP and dictates invasion and metastasis in breast cancer. J Cell Sci 127:3893-3901

16. Hernandez-Fernaud JR, Ruengeler E, Casazza A, Neilson LJ, Pulleine E, Santi A, Ismail S, Lilla S, Dhayade S, MacPherson IR, McNeish I, Ennis D, Ali $H$, Kugeratski FG, Al Khamici H, van den Biggelaar M, van den Berghe PV, 
Cloix C, McDonald L, Millan D, Hoyle A, Kuchnio A, Carmeliet P, Valenzuela SM, Blyth K, Yin H, Mazzone M, Norman JC, Zanivan S (2017) Secreted CLIC3 drives cancer progression through its glutathione-dependent oxidoreductase activity. Nat Commun 8:14206

17. Tasiopoulou V, Magouliotis D, Solenov El, Vavougios G, Molyvdas PA, Gourgoulianis KI, Hatzoglou C, Zarogiannis SG (2015) Transcriptional overexpression of chloride intracellular channels 3 and 4 in malignant pleural mesothelioma. Comput Biol Chem 59:111-116

18. Isozaki H, Fujii K, Nomura E, Mabuchi H, Hara H, Sako S, Nishiguchi K, Ohtani M, Tenjo T, Nohara T, Tanigawa N (1998) Prognostic value of tumor cell proliferation and intratumor microvessel density in advanced gastric cancer treated with curative surgery. Int J Oncol 13:255-259

19. Duff D, Long A (2017) Roles for RACK1 in cancer cell migration and invasion. Cell Signal 35:250-255

20. Oudin MJ, Weaver VM (2016) Physical and chemical gradients in the tumor microenvironment regulate tumor cell invasion, migration, and metastasis. Cold Spring Harb Symp Quant Biol 81:189-205
21. Miyazaki H, Shiozaki A, Niisato N, Ohsawa R, Itoi H, Ueda Y, Otsuji E, Yamagishi H, Iwasaki Y, Nakano T, Nakahari T, Marunaka Y (2008) Chloride ions control the $G_{1} / S$ cell-cycle checkpoint by regulating the expression of p21 through a p53-independent pathway in human gastric cancer cells. Biochem Biophys Res Commun 366:506-512

22. Tanaka S, Miyazaki H, Shiozaki A, Ichikawa D, Otsuji E, Marunaka Y (2017) Cytosolic $\mathrm{Cl}^{-}$affects the anticancer activity of paclitaxel in the gastric cancer cell line, MKN28 cell. Cell Physiol Biochem 42:68-80

23. Hiraoka K, Miyazaki H, Niisato N, Iwasaki Y, Kawauchi A, Miki T, Marunaka Y (2010) Chloride ion modulates cell proliferation of human androgenindependent prostatic cancer cell. Cell Physiol Biochem 25:379-388

\section{Publisher's Note}

Springer Nature remains neutral with regard to jurisdictional claims in published maps and institutional affiliations.
Ready to submit your research? Choose BMC and benefit from:

- fast, convenient online submission

- thorough peer review by experienced researchers in your field

- rapid publication on acceptance

- support for research data, including large and complex data types

- gold Open Access which fosters wider collaboration and increased citations

- maximum visibility for your research: over 100M website views per year

At BMC, research is always in progress.

Learn more biomedcentral.com/submissions 